\title{
Clinical and genetic aspects of Angelman syndrome
}

\author{
Charles A. Williams, MD, Daniel J. Driscoll, MD, PhD, and Aditi I. Dagli, MD
}

TABLE OF CONTENTS

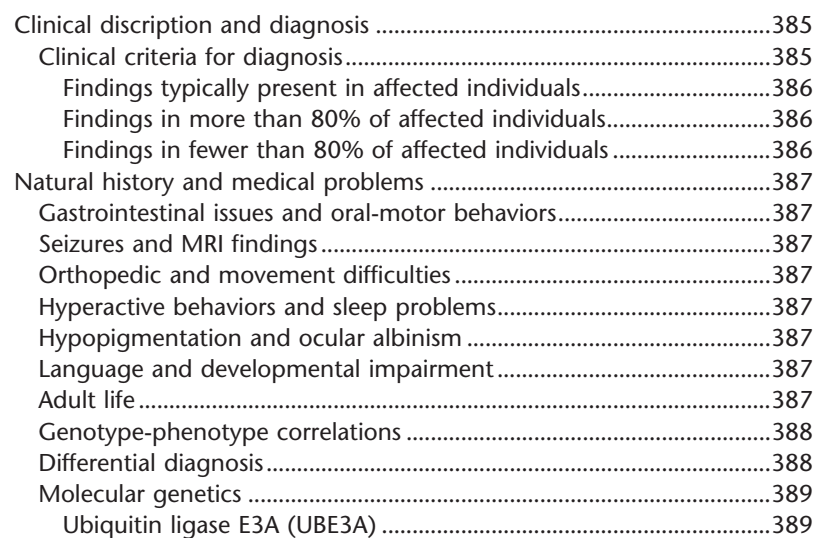

Abstract: Angelman syndrome is characterized by severe developmental delay, speech impairment, gait ataxia and/or tremulousness of the limbs, and a unique behavioral phenotype that includes happy demeanor and excessive laughter. Microcephaly and seizures are common. Developmental delays are first noted at 3 to 6 months age, but the unique clinical features of the syndrome do not become manifest until after age 1 year. Management includes treatment of gastrointestinal symptoms, use of antiepileptic drugs for seizures, and provision of physical, occupational, and speech therapy with an emphasis on nonverbal methods of communication. The diagnosis rests on a combination of clinical criteria and molecular and/or cytogenetic testing. Analysis of parent-specific DNA methylation imprints in the 15q11.2-q13 chromosome region detects $\sim 78 \%$ of individuals with lack of maternal contribution. Less than $1 \%$ of individuals have a visible chromosome rearrangement. $U B E 3 A$ sequence analysis detects mutations in an additional $11 \%$ of individuals. The remaining $10 \%$ of individuals with classic phenotypic features of Angelman syndrome have a presently unidentified genetic mechanism and thus are not amenable to diagnostic testing. The risk to sibs of a proband depends on the genetic mechanism of the loss of the maternally contributed Angelman syndrome/Prader-Willi syndrome region: typically $<1 \%$ for probands with a deletion or uniparental disomy; as high as $50 \%$ for probands with an imprinting defect or a mutation of $U B E 3 A$. Members of the mother's extended family are also at increased risk when an imprinting defect or a $U B E 3 A$ mutation is present. Chromosome rearrangements may be inherited or de novo. Prenatal testing is

From the Raymond C. Philips Research and Education Unit, Division of Genetics and Metabolism, Department of Pediatrics, University of Florida College of Medicine, Gainesville, Florida.

Charles A. Williams, MD, P.O. Box 100296, HSC, Gainesville, FL 32610. E-mail: willicx@peds.ufl.edu.

Disclosure: The authors have no conflicts of interests.

Submitted for publication February 1, 2010.

Accepted for publication March 11, 2010.

Published online ahead of print May 4, 2010.

DOI: $10.1097 /$ GIM.0b013e3181def138

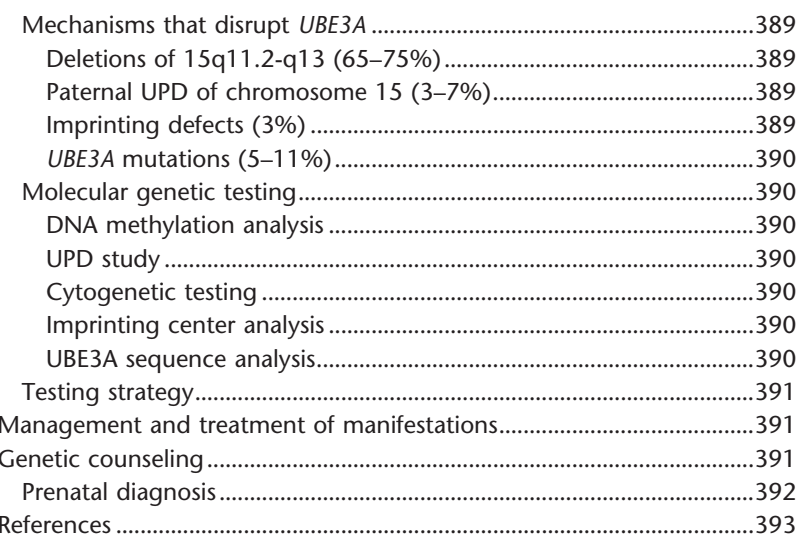

possible for certain genetic mechanisms. Genet Med 2010:12(7): 385-395.

Key Words: Angelman syndrome, UBE3A, imprinting, imprinting center, 15q11.2, microdeletion

ngelman syndrome (AS) is seen in one in 12,000-20,000 of Athe population ${ }^{1-3}$ and is characterized by severe developmental delay and speech impairment, gait ataxia and/or tremulousness of the limbs, and a unique behavior with a happy demeanor that includes frequent laughing, smiling, and excitability. $^{4-7}$ In addition, microcephaly and seizures are common. Developmental delays are first noted at around age 6 months; however, the unique clinical features of AS do not become manifest until after age 1 year, and it can take several years before the correct clinical diagnosis is made.

In the last decade, AS has emerged as an important genetic syndrome involving childhood epilepsy and severe developmental delay. The timely diagnosis of AS poses a challenge to the clinician because there may be no obvious dysmorphic features or specific clinical caveats in infancy that easily point to the diagnosis. The behavioral phenotype is a crucial element in suspecting the diagnosis but this may not be manifest in a particular clinical encounter. Another challenge for the clinician is the multiple genetic mechanisms that cause AS, each by disrupting the $U B E 3 A$ gene. Accordingly, several diagnostic genetic tests may be necessary to confirm the diagnosis. Finally, the phenomenon of genomic imprinting adds to the complexity of AS, particularly as it relates to accurate genetic counseling. In the following sections, we review the current clinical and genetic aspects of this important neurogenetic condition.

\section{CLINICAL DISCRIPTION AND DIAGNOSIS}

\section{Clinical criteria for diagnosis}

Consensus criteria for the clinical diagnosis of AS have been developed in conjunction with the Scientific Advisory Commit- 
tee of the US Angelman Syndrome Foundation. ${ }^{7}$ Newborns typically have a normal phenotype. Developmental delays are first noted at around age 6 months. However, the unique clinical features of AS do not become manifest until after age 1 year, and it can take several years before the correct clinical diagnosis is obvious. The diagnosis is usually first suspected on the basis of the behavioral phenotype, particularly combinations of movement disorder, absent speech, and happy demeanor. Although some individuals with AS may have apparent mild craniofacial dysmorphism, the diagnosis is rarely suspected based on these findings (Fig. 1).

\section{Findings typically present in affected individuals}

- Normal prenatal and birth history, normal head circumference at birth, no major birth defects.

- Normal metabolic, hematologic, and chemical laboratory profiles.

- Structurally normal brain by magnetic resonance imaging (MRI) or computed tomography, although mild cortical atrophy or dysmyelination may be observed.

- Delayed attainment of developmental milestones without loss of skills.

- Evidence of developmental delay by age 6 to 12 months, eventually classified as severe.

- Speech impairment, with minimal to no use of words; receptive language skills and nonverbal communication skills higher than expressive language skills.
- Movement or balance disorder, usually ataxia of gait and/or tremulous movement of the limbs.

- Behavioral uniqueness, including any combination of frequent laughter/smiling; apparent happy demeanor; excitability, often with hand-flapping movements; hypermotoric behavior; short attention span.

\section{Findings in more than $80 \%$ of affected individuals}

- Delayed or disproportionately slow growth in head circumference, usually resulting in absolute or relative microcephaly by age 2 years.

- Seizures, usually starting before age 3 years.

- Abnormal electroencephalogram (EEG), with a characteristic pattern of large-amplitude slow-spike waves.

\section{Findings in fewer than $80 \%$ of affected individuals}

- Flat occiput.

- Occipital groove.

- Protruding tongue.

- Tongue thrusting; suck/swallowing disorders.

- Feeding problems and/or muscle hypotonia during infancy.

- Prognathia.

- Wide mouth, wide-spaced teeth.

- Frequent drooling.

- Excessive chewing/mouthing behaviors.

- Strabismus.

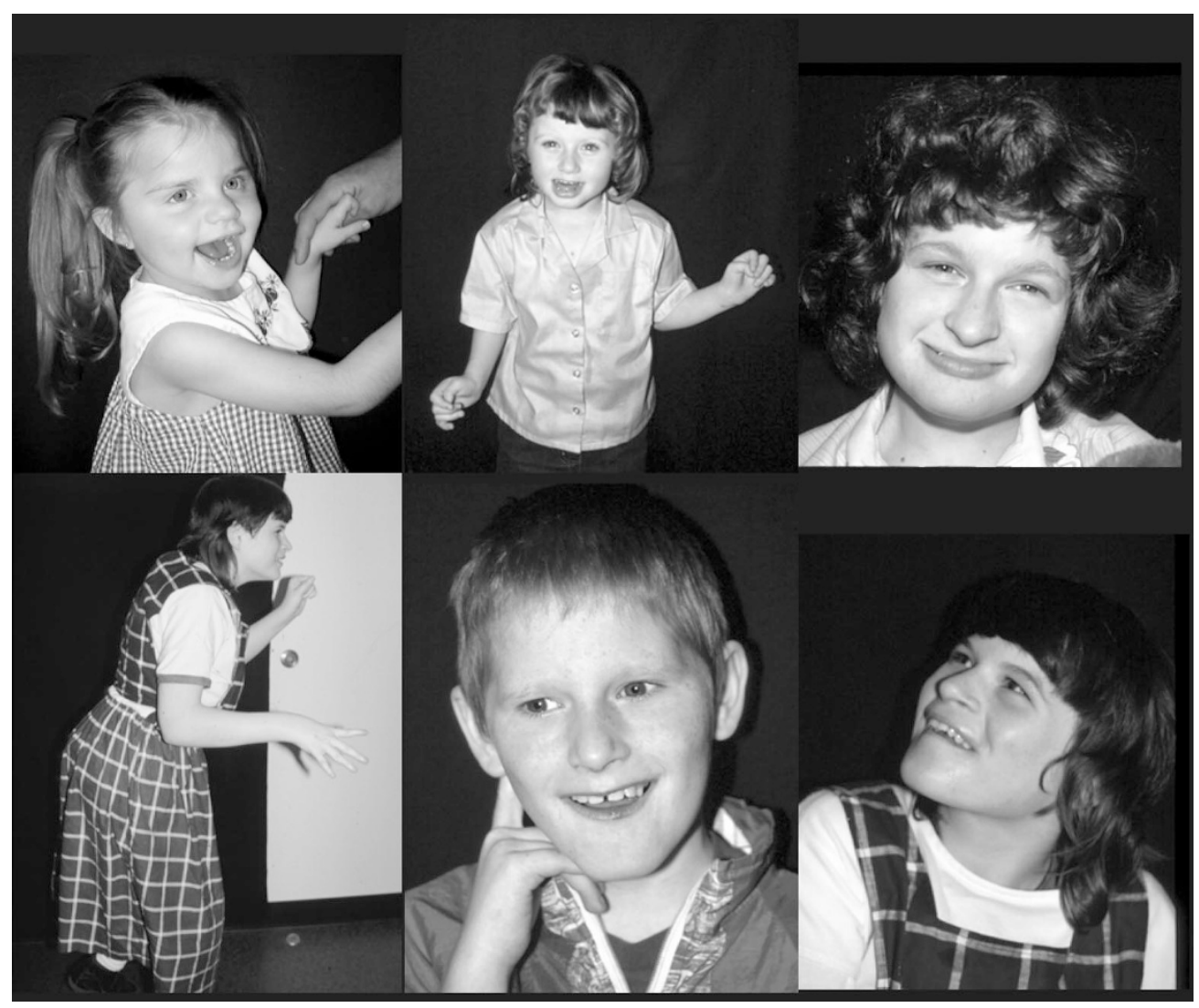

Fig. 1. Individuals depicted have a genetically confirmed diagnosis of AS. A happy expression and unstable gait, accompanied by uplifted arms, are commonly observed. At times, the facial appearance can suggest the syndromic diagnosis but usually there is no significant facial dysmorphism. 
- Hypopigmented skin, light hair and eye color (compared with family); seen only in those with a deletion.

- Hyperactive lower-extremity deep-tendon reflexes.

- Uplifted, flexed arm position especially during ambulation.

- Wide-based gait with out-going (i.e., pronated or valguspositioned) ankles.

- Increased sensitivity to heat.

- Abnormal sleep-wake cycles and diminished need for sleep.

- Attraction to/fascination with water; fascination with crinkly items such as certain papers and plastics.

- Abnormal food-related behaviors.

- Obesity (in the older child; more common in those who do not have a deletion).

- Scoliosis.

- Constipation.

\section{NATURAL HISTORY AND MEDICAL PROBLEMS}

\section{Gastrointestinal issues and oral-motor behaviors}

Feeding problems are frequent but not generally severe and usually appear early as difficulty in sucking or swallowing. ${ }^{8-10}$ Tongue movements may be uncoordinated with thrusting and generalized oral-motor incoordination. There may be trouble initiating sucking and sustaining breastfeeding, and bottle feeding may prove easier. Frequent spitting up may be interpreted as formula intolerance or gastroesophageal reflux. Infrequently, severe gastroesophageal reflux may require surgery. AS children are notorious for putting everything in their mouths. In early infancy, hand sucking (and sometimes foot sucking) is frequent. Later, most exploratory play is by oral manipulation and chewing. Many but not all have tongue protrusion and drooling whereas others have protrusion that is noticeable only during laughter.

\section{Seizures and MRI findings}

Seizures typically occur between ages 1 and 3 years and can be associated with generalized, somewhat specific EEG changes: runs of high-amplitude delta activity with intermittent spike and slow-wave discharges (at times observed as a notched delta pattern); runs of rhythmic theta activity over a wide area; and runs of rhythmic sharp theta activity of 5-6/second over the posterior third of the head, forming complexes with small spikes. These are usually facilitated by or seen only with eye closure. ${ }^{11-13}$ Seizure types can be quite varied and include both major and minor motor types. ${ }^{14}$ Infantile spasms are rare. Brain MRI shows no malformation but may show mild atrophy and mild dysmyelination or hypomyelination. ${ }^{15,16}$ There have been individual cases reported with brain malformations such as vermian cyst, split cord malformation, and intracranial aneurysm ${ }^{17-20}$ or other types of physical and neurological problems such as vagal hypertonia, Parkinsonism, premature thelarche, limb deformities, myoclonus, and hyper-reflexia. ${ }^{21-26}$ These most likely represent coincidental occurrences.

\section{Orthopedic and movement difficulties}

Hyperkinetic movements of the trunk and limbs have been noted in early infancy ${ }^{10}$ and jitteriness or tremulousness may be present in the first 6 months of life. Voluntary movements are often irregular, varying from slight jerkiness to uncoordinated coarse movements that prevent walking, feeding, and reaching for objects. Gross motor milestones are delayed; sitting usually occurring after age 12 months and walking often delayed until age 3 to 5 years. ${ }^{8,27}$ In early childhood, the mildly impaired child can have almost normal walking. There may be only mild toe-walking or an apparent prancing gait. More severely affected children can be stiff and robot-like or extremely shaky and jerky when walking. The legs are kept wide-based and the feet are often flat and ankles pronated and turned outward. This, accompanied by uplifted arms, flexed elbows and downward turned hands, produces the characteristic gait of AS. Some children are so ataxic and jerky that walking is not possible until they are older and better able to compensate motorically for the jerkiness; about $10 \%$ may fail to achieve walking. ${ }^{1}$

\section{Hyperactive behaviors and sleep problems}

Sleep disorders are common, especially frequent night waking and early awakening. ${ }^{28,29}$ Decreased need for sleep and abnormal sleep/wake cycles are characteristic of AS. ${ }^{28,30,31}$ Essentially, all young children with AS have some component of hyperactivity; men and women appear equally affected. Infants and toddlers may have seemingly ceaseless activity, constantly keeping their hands or toys in their mouth, moving from object to object. Short attention span is present in most. Some behaviors may suggest an autism spectrum problem but social engagement is typically good and stereotypical behaviors such as lining up of toys or fascination with spinning objects or flashing lights rarely occur. ${ }^{32}$

\section{Hypopigmentation and ocular albinism}

When AS is caused by the large deletion, skin and eye hypopigmentation can occur and is attributed to haploinsufficiency of the $O C A 2$ gene (also termed the $P$ gene), located close to $U B E 3 A .^{33}$ The $O C A 2$ gene encodes a protein important in tyrosine metabolism that is associated with the development of pigment in the skin, hair, and irides. In some children with AS, this hypopigmentation can be so severe that a form of albinism is suspected. ${ }^{34,35}$ When AS is caused by the other genetic mechanisms, normal skin and eye pigmentation is seen. Not all AS children with deletions of the OCA2 gene are obviously hypopigmented but may only have relatively lighter skin color than either parent.

\section{Language and developmental impairment}

Language impairment is severe. Appropriate use of even one or two words in a consistent manner is rare. Receptive language skills are always more advanced than expressive language skills. ${ }^{36}$ Most older children and adults with AS are able to communicate by pointing and using gestures and by using communication boards. Conversational speech does not develop even in high functioning individuals. ${ }^{37}$ Effective fluent use of sign language does not occur. ${ }^{38}$

Cognitive abilities are profoundly affected. Accurate developmental testing is difficult because of inability to pay attention, hyperactivity, and lack of speech. Psychometric testing suggests that the upper developmental potential is in the 24-30 month range. ${ }^{29,36,39}$ Individuals with difficult to control seizures may be more impaired. However, with consistent interventions and stimulation children show improved development.

\section{Adult life}

Pubertal onset and development are generally normal in AS and procreation appears possible for both men and women. Fertility appears to be normal; Lossie and Driscoll ${ }^{40}$ reported transmission of an AS deletion to a fetus by the affected mother.

Independent living is not possible for adults with $\mathrm{AS}$, but most can live at home or in home-like placements. Life span does not appear to be dramatically shortened in AS but may be decreased by $10-15$ years. There are reports of AS individuals 
living beyond 70 years although there is as of yet no actuarial data that estimates life span. ${ }^{41,42}$

\section{Genotype-phenotype correlations}

All genetic mechanisms that give rise to AS lead to a somewhat uniform clinical picture of severe-to-profound mental retardation, movement disorder, characteristic behaviors, and severe limitations in speech and language. However, some clinical differences correlate with genotype. ${ }^{43-46}$ The 5-7 Mb deletion class results in the most severe phenotype with microcephaly, seizures, motor difficulties (e.g., ataxia, muscular hypotonia, feeding difficulties), and language impairment. Those with the large deletion are more likely to exhibit clinical hypopigmentation (discussed above). There is some suggestion that individuals with larger deletions (e.g., BP1-BP3 [class I] break points) may have more language impairment or autistic traits ${ }^{47}$ than those with BP2-BP3 (class II) break points (Fig. 2). Individuals with uniparental disomy (UPD) have better physical growth (e.g., less likelihood of microcephaly), fewer movement abnormalities, less ataxia, and a lower prevalence (but not absence) of seizures compared with those with other underlying molecular mechanisms. ${ }^{44,48}$ Individuals with an imprinting defect (ID) or with UPD have higher developmental and language ability than those with other underlying molecular mechanisms. Individuals who are mosaic for the nondeletion ID (approximately 20\% of the ID group) have the most advanced speech abilities ${ }^{49}$; they may speak up to 50-60 words and use simple sentences. These individuals may not be suspected initially to have AS because their gait may not appear abnormal and their speech ability may seem too advanced, thus appropriate diagnostic testing may not be requested.

\section{Differential diagnosis}

Infants with AS commonly present with nonspecific psychomotor delay and/or seizures and so the differential diagnosis is often broad and nonspecific, encompassing entities such as cerebral palsy, static encephalopathy, and mitochondrial encephalomyopathy. Tremulousness and jerky limb movements seen in most infants with AS may help to distinguish AS from these conditions.

Mowat-Wilson syndrome can present with findings that suggest AS, ${ }^{50}$ including happy affect, prominent mandible, diminished speech, microcephaly, and constipation. Mowat-Wilson syndrome typically results from heterozygous mutations in ZEB2.

Christianson syndrome, an X-linked disorder, can mimic AS and involves mutations in the SLC9A6 gene. The clinical features include apparently happy disposition, severe cognitive delays, ataxia, microcephaly, and a seizure disorder. ${ }^{51,52}$ Some may have cerebellar and brain stem atrophy. ${ }^{51}$ Although seizures are present in both conditions, the EEG pattern appears to be different. AS typically shows a generalized high amplitude, slow spike/wave (1.5-3 Hz) pattern whereas those with SLC9A6 mutations lack the AS EEG pattern and have a more rapid (10-14 Hz) background frequency. ${ }^{51}$ Individuals with SLC9A6 disorder may have thinner body appearance and may lose ambulation beyond 10 years of age.

Adenylosuccinate lyase deficiency results in accumulation of succinylpurines leading to psychomotor retardation, autistic features, hypotonia, and seizures. ${ }^{53}$ Motor apraxia, severe speech deficits, excessive laughter, a very happy disposition, hyperactivity, a short attention span, mouthing of objects, tantrums, and stereotyped movements have been reported in female sibs by Gitiaux et al. ${ }^{54}$

The characteristic features of Pitt-Hopkins syndrome are mental retardation, wide mouth and distinctive facial features, and intermittent hyperventilation followed by apnea. ${ }^{55}$ It may have overlapping features with AS such as microcephaly, seizures, ataxic gait, and happy personality. Diurnal hyperventilation is a salient feature in some and occurs after 3 years of age. ${ }^{56}$ Mutation and deletion screening for the TCF4 gene is available.

Infant girls with AS having seizures and severe speech impairment can resemble Rett syndrome, but children with AS do not have a regressive course and do not lose purposeful use of their hands, as do girls with Rett syndrome. Older girls with undiagnosed Rett syndrome may also have features that resem-
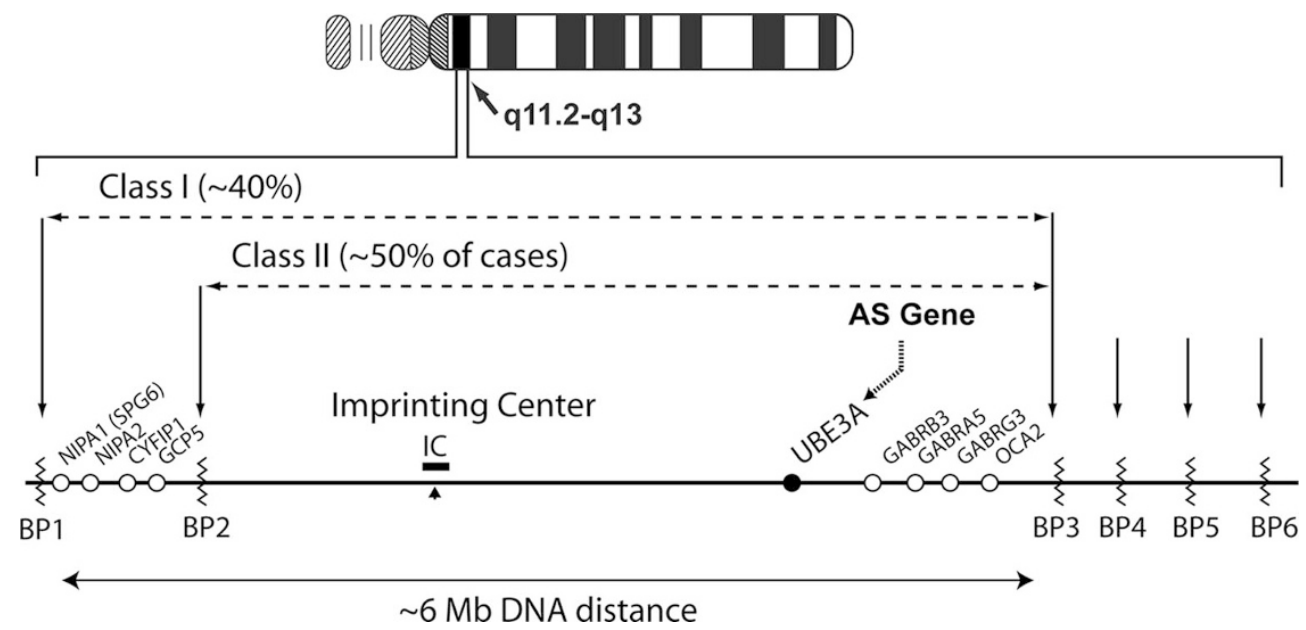

Fig. 2. Schematic organization of the 15q11.2-q13 genomic region. Location of the AS gene, UBE3A, is indicated by the arrow. Break points (BPs), where low copy repeats are located, are indicated by the vertical arrows and jagged lines; the most common Class I and Class II deletions are noted by the dashed lines; larger but less frequently occurring deletions extend from BP1 or BP2 to BP4 or more distant BP locations. The IC is depicted, located approximately $500 \mathrm{~Kb}$ centromeric to UBE3A. 
ble AS, leading to the erroneous clinical diagnosis of AS. ${ }^{57}$ Testing for mutations of $M E C P 2$ is widely available.

Sometimes infants with AS who present with feeding difficulties and muscle hypotonia are misdiagnosed as having Prader-Willi syndrome (PWS) because the 15q11.2-q13 deletion, detected by comparative genomic hybridization (CGH) or fluorescent in situ hybridization (FISH), was not proven by DNA methylation analysis to be of maternal origin.

Other chromosome disorders can also mimic some of the features of AS, especially the 22q13.3 deletion (Phelan-McDermid) syndrome. ${ }^{58}$ This condition may present with nondysmorphic facial features, absent or minimal speech, and moderate to severe developmental delay, sometimes with behavioral features in the autism spectrum. Microdeletions of the 2q23.1 region may result in severe speech delay, seizures, behavioral disorders, and microcephaly. Some individuals present with an AS-like phenotype. ${ }^{59,60}$ Other microdeletion disorders, especially newer ones detected by $\mathrm{CGH}$ may be associated with some features of AS. ${ }^{61,62}$

\section{Molecular genetics}

\section{Ubiquitin ligase E3A (UBE3A)}

The cardinal features of AS result from deficient expression or function of the maternally inherited $U B E 3 A$ allele. ${ }^{44,63-66}$ $U B E 3 A$ produces the 865 -amino acid E6-associated protein (E6AP), which acts as a cellular ubiquitin ligase enzyme. It was first discovered as the protein able to associate with p53 in the presence of the E6 oncoprotein of the human papilloma virus, type $16 .{ }^{67,68}$ The E6AP enzyme catalyzes a covalent linkage between the 76-amino acid ubiquitin molecule and its target protein. ${ }^{69,70}$ This reaction occurs in a catalytic region of E6AP termed the homologous to E6AP C terminus (HECT) domain. ${ }^{71}$ After ubiquitin attachment, E6AP can add ubiquitins onto the first ubiquitin to create a polyubiquitylated substrate that can then be targeted for degradation through the 26S proteasome complex. The E6AP is one of many E3 ligases that function in the E3 component of the ubiquitin cycle; E1 and E2 proteins respectively activate and transfer the ubiquitin to E3. UBE3A also contains a steroid receptor coactivation domain located upstream of the HECT region. ${ }^{72}$ This domain has been much less studied from the standpoint of $U B E 3 A$ 's role in neural development.

$U B E 3 A$ and the $26 \mathrm{~S}$ proteosome pathway are essential for many cellular functions including signal transduction and transcriptional regulation. ${ }^{69,70}$ Disruption of $U B E 3 A$ could affect multiple neuronal processes such as membrane receptor turnover and other protein events necessary to enable normal synaptic function and plasticity. Several proteins have been identified as potential targets of E6AP, ${ }^{73-80}$ but it is not yet evident how any of these are involved in the neuropathogenesis of AS. Studies in AS animal models indicate that disruption of $U B E 3 A$ leads to truncated dendritic processes, ${ }^{81,82}$ impairments of neural plasticity particularly as evidenced by defects in long-term potentiation ${ }^{83,84}$ and dysfunction of a postsynaptic kinase pathways involving calmodulin-dependent protein kinase II. ${ }^{85,86}$

$U B E 3 A$ displays predominant maternal expression in human fetal brain and adult frontal cortex. ${ }^{87-89}$ In mouse, maternal allele-specific expression is detected in specific brain subregions including hippocampus, cerebellum, olfactory bulb, and visual cortex. ${ }^{83,84,90}$ Other brain regions may also show this type of allele-specific expression. Primary cell cultures from fetal mouse brain reveal that $U B E 3 A$ imprinting is limited to neurons and that glial cells show biallelic expression. ${ }^{91}$ There is preferential maternal expression of $U B E 3 A$ in lymphoblasts and fi- broblasts but the differential expression between the parental alleles is not as striking as it is in brain. ${ }^{92} U B E 3 A$ has a large $5^{\prime}$ $\mathrm{CpG}$ island but its DNA methylation does not differ between the maternal and paternal alleles. ${ }^{44}$ Because no differentially methylated promoter region is present in $U B E 3 A$, it has been proposed that the imprinted expression of $U B E 3 A$ may be regulated indirectly through a paternally expressed antisense transcript. ${ }^{93}$ Runte et al. ${ }^{94}$ have shown that a long SNURF-SNRPN sense/ $U B E 3 A$ antisense RNA transcript exists in the AS/PWS region, starting from the $S N U R F-S N R P N$ imprinting center (IC) and extending more than $460 \mathrm{~kb}$ to at least the $5^{\prime}$ end of $U B E 3 A$. It has been proposed that this $U B E 3 A$ antisense transcript blocks paternal $U B E 3 A$ gene expression. $U B E 3 A$ spans approximately $120 \mathrm{~kb}$ of genomic DNA and contains 16 exons. The $5^{\prime}$ untranslated region (UTR) extends several kilobases upstream from the initiation site and spans an additional six to nine exons, ${ }^{65,89,95,96}$ whereas the $3^{\prime}$ UTR extends an additional 2.0 $\mathrm{kb} .{ }^{95}$ To date, alternative splicing of the 5' UTR accounts for the production of nine adult and two fetal transcripts, ${ }^{65,89,95,96}$ which are translated into three different protein isoforms.

\section{Mechanisms that disrupt UBE3A}

\section{Deletions of 15q11.2-q13 (65-75\%)}

Three chromosomal break points (proximal BP1, BP2, and a distal BP3) are involved in most AS-causing deletion events involving 15q11.1-q13, and these deletions span approximately 5-7 $\mathrm{Mb}^{97-99}$ (Fig. 2). Fewer than $10 \%$ of individuals with AS may have deletions extending from the $\mathrm{BP} 1 / \mathrm{BP} 2$ region to regions more distal, at BP4 or BP5 locations (Fig. 2). ${ }^{47}$ The $\mathrm{BP} 1, \mathrm{BP} 2$, and $\mathrm{BP} 3$ regions are characterized by low-copy repeat regions that contain repeats mainly derived from the ancestral HECT domain and $\mathrm{RCc1}$ domain protein 2 genes (HERC2). ${ }^{100}$ The BP sites distal to BP3 contain other low-copy repeat regions (e.g., without $H E R C 2$ duplications) that share chromosome 15-derived repeated DNA elements. A proportion of mothers who have a child with an AS deletion have been found to have inversions in the $15 \mathrm{q} 11.2 \mathrm{-q} 13$ region (the region deleted in the offspring with AS). ${ }^{101}$ Also, a kindred in which two individuals had deletions (one deletion causing PWS and the other causing AS) has been previously reported to be associated with an inherited paracentric inversion of $15 \mathrm{q} 11.2-\mathrm{q} 13 .{ }^{38}$ It is thus possible that in otherwise normal individuals, such preexisting genomic abnormalities may predispose to deletion of 15q11.2-q13 in the germline resulting in offspring with AS.

Interstitial duplications of $15 \mathrm{q} 11.2-\mathrm{q} 13$ on the maternally derived chromosome cause a disorder clinically distinct from either AS or PWS. Individuals with dup15q11.2-q13 do not have facial dysmorphism but have mild to moderately severe learning deficits and may have behaviors in the autism spectrum. ${ }^{102}$

\section{Paternal UPD of chromosome 15 (3-7\%)}

Individuals with paternal UPD tend to have a milder presentation with lower incidence of seizures. ${ }^{44,103}$ In contrast to PWS, the paternal UPD observed in AS is most likely to be postzygotic in origin. ${ }^{104}$

\section{Imprinting defects (3\%)}

This subset of individuals with AS have a defect in the mechanism(s) involved in resetting the imprint during gametogenesis. Genetic (small deletions) and epigenetic (abnormal DNA methylation pattern but no deletion) defects in the IC within 15q11.2-q13 change the DNA methylation and expression imprints along 15q11.2-q13. Even though these individuals 
have biparental inheritance of chromosome 15, the maternal $15 q 11.2$-q13 region has a paternal epigenotype and is therefore transcriptionally incompetent for the maternal-only expressed gene(s) in this region. ${ }^{105-107}$ Microdeletions in the IC (Fig. 2), varying in size from 6 to $200 \mathrm{~kb}$, have been found between the PW71 locus and the SNRPN gene in individuals with both AS and PWS. ${ }^{105,106}$ The smallest deletion of the IC region common among this subset of AS cases has been narrowed to 880 base pairs, ${ }^{108}$ which is approximately $30 \mathrm{~kb}$ proximal to the smallest IC region deletion common among PWS cases. Most individuals with AS caused by IC defects do not have a deletion of the AS IC region, but rather have epigenetic defects that disrupt IC function.

\section{UBE3A mutations (5-11\%)}

Sequence analysis of individuals with AS reveals that the majority of $U B E 3 A$ mutations result in (or predict) protein truncation $44,65,66,95,109,110$ without evidence of any hot spot location. It is possible that individuals with milder mutations (e.g., missense and in frame deletions) may show some, but not all, of the clinical features associated with AS. A few individuals with AS have been found to have complete or partial deletions of $U B E 3 A$, or to have intragenic deletions. These may be detected by special quantitative polymerase chain reaction study. ${ }^{111}$ Although CGH usually detects large 15q11.2-13 deletions, in rare instances array $\mathrm{CGH}$ has detected $U B E 3 A$ multiexonic or whole-gene deletions. ${ }^{112,113}$ Deletions detected vary by test method and laboratory; detection of large intragenic deletions may require molecular methods available only in a research laboratory.

\section{Molecular genetic testing}

\section{DNA methylation analysis}

Unaffected individuals have a methylated and an unmethylated SNRPN allele in both the Southern blot analysis ${ }^{114}$ and methylation-specific polymerase chain reaction assay. ${ }^{115,116} \mathrm{In}-$ dividuals with AS caused by a 5-7 Mb deletion of 15q11.2-q13, UPD, or an ID have only an unmethylated (i.e., "paternal") contribution (i.e., an abnormal parent-specific DNA methylation imprint). Most commercially available DNA methylation analysis tests cannot distinguish between AS resulting from a deletion, from UPD, and from an ID. Further testing is required to identify the underlying molecular mechanism as outlined in Testing Strategy. Newer methods involving pyrosequencing, ${ }^{117}$ methylation-specific multiplex ligation-dependent probe amplification, ${ }^{118,119}$ sequence-based quantitative methylation analysis, ${ }^{120}$ and other methods ${ }^{121}$ of copy-number analysis may soon provide sufficient quantitation to differentiate deletions from an ID or from UPD.

FISH or array-based CGH (array CGH): In $68 \%$ of individuals, 5-7 Mb deletions are detected by FISH, array CGH, or any of various deletion testing methods (Table 1). FISH analysis with the D15S10 and/or the SNRPN probe can identify the deletion, but typically the deletion is not detected by routine cytogenetic analysis.

\section{UPD study}

In approximately $7 \%$ of individuals, UPD is detected using DNA polymorphism testing, which requires a DNA sample from the proband and both parents.

\section{Cytogenetic testing}

Less than $1 \%$ of individuals with AS have a cytogenetically visible chromosome rearrangement (i.e., translocation or inversion) of one number 15 chromosome involving 15q11.2-q13.

\section{Imprinting center analysis}

IDs account for approximately $3 \%$ of affected individuals. They have an abnormal DNA methylation imprint but have a normal FISH or array CGH study and no evidence of UPD. Approximately $10-20 \%$ of the IDs are caused by microdeletions $(6-200 \mathrm{~kb})$ that include the AS IC. These microdeletions are detected by any of various methods used for deletion analysis (Table 1). The other $80-90 \%$ of IDs are thought to be epigenetic mutations occurring during maternal oogenesis or in early embryogenesis. ${ }^{105,106}$ Characterization of the ID as either an IC deletion or epigenetic defect is available in only a few clinical laboratories.

\section{UBE3A sequence analysis}

When the DNA methylation test is normal, UBE3A sequence analysis should be considered for individuals with clinical features of AS. Approximately $11 \%$ of individuals with AS have an identifiable $U B E 3 A$ mutation. ${ }^{44,109,122}$ A few individuals with AS have multiexonic or whole gene deletions of $U B E 3 A$. These deletions are detected by any of various methods used for deletion analysis (Table 1). In addition, some array-CGH platforms may be able to detect some of these deletions. ${ }^{112,113}$

Table 1 summarizes molecular genetic testing. Possible explanations for the failure to detect AS-causing genetic abnormalities in the $11 \%$ or more of individuals with clinically diagnosed AS include incorrect clinical diagnosis, undetected mutations in the regulatory region(s) of $U B E 3 A$, and other

Table 1 Molecular genetic testing used in AS after DNA methylation analysis

\begin{tabular}{|c|c|c|c|c|c|}
\hline $\begin{array}{l}\text { Parent-specific DNA } \\
\text { methylation imprint }\end{array}$ & $\begin{array}{l}\text { Locus, gene, or } \\
\text { chromosome }\end{array}$ & Test methods & Mutations detected & $\begin{array}{l}\text { Frequency of } \\
\text { mutation detection }^{a}\end{array}$ & $\begin{array}{c}\text { Test } \\
\text { availability }\end{array}$ \\
\hline \multirow[t]{3}{*}{ Abnormal } & AS/PWS region & FISH or $\mathrm{CGH}$ & $5-7 \mathrm{Mb}$ deletion of $15 \mathrm{q} 11.2-\mathrm{q} 13$ & $\sim 68 \%$ & Clinical \\
\hline & Chromosome 15 & UPD study & UPD & $\sim 7 \%$ & \\
\hline & AS IC & Deletion analysis $^{b}$ & $6-200 \mathrm{~kb}$ deletions & $\sim 3 \%$ & \\
\hline \multirow[t]{2}{*}{ Normal } & $U B E 3 A$ & Sequence analysis & Sequence variants & $\sim 11 \%$ & \\
\hline & & $\begin{array}{c}\text { Gene or intragenic } \\
\text { deletion study }\end{array}$ & $\begin{array}{l}\text { Partial or whole-gene } \\
\text { deletions }\end{array}$ & Rare & \\
\hline
\end{tabular}

${ }^{a}$ Eleven percent of individuals with the presumptive clinical diagnosis of AS have normal results for all testing methods described in this table

${ }^{b}$ Deletion analysis of the AS IC detects small deletions, which account for $10-20 \%$ of IDs. 
unidentified mechanisms or gene(s) involved in disrupting $U B E 3 A$ function.

\section{Testing strategy}

DNA methylation analysis identifies approximately $80 \%$ of individuals with AS and is typically the first test ordered. If the DNA methylation analysis is abnormal, the next step is FISH or array $\mathrm{CGH}$ analysis. If a deletion is found, a chromosome rearrangement (rarely observed) should be excluded. Methylation analysis and UPD studies do not detect chromosomal rearrangements. If the FISH or array $\mathrm{CGH}$ analysis is normal, analysis of DNA polymorphisms on chromosome 15 can distinguish between UPD and an ID. If there is no UPD, further DNA studies can determine if an IC deletion is present. If DNA methylation is normal, $U B E 3 A$ sequence analysis is the next appropriate diagnostic test.

\section{MANAGEMENT AND TREATMENT OF MANIFESTATIONS}

Feeding problems in newborns may require special nipples and other strategies to manage weak or uncoordinated sucking. Gastroesophageal reflux can be associated with poor weight gain and emesis; the customary medical treatment (i.e., upright positioning, motility drugs) is usually effective; sometimes fundoplication as required. Excessive tongue protrusion causes drooling; available surgical or medication treatments (e.g., surgical reimplantation of the salivary ducts or use of local scopolamine patches) are generally not effective.

Many antiepileptic drugs are used to treat seizures in individuals with AS but there is no agreement as to the optimal seizure medication although valproic acid (Depakote), topiramate (Topamax), lamotrigine (Lamictal), levetiracetam (Keppra), and clonazepam (Klonopin) are more commonly used in the North America. Carbamazepine (Tegretol), ethosuximide (Zarontin), phenytoin (Dilantin), phenobarbital, and adrenocorticotropic hormone are less commonly used. ${ }^{123}$ Carbamazepine, oxcarbazepine (Trileptal), and vigabatrin (Sabril) have been noted to cause paradoxical aggravation of seizures in some individuals with AS, but their use in AS is not absolutely contraindicated. ${ }^{124-129}$ Single medication use is preferred but seizure breakthrough is common. Children with AS are at risk for medication over-treatment because their movement abnormalities or attention deficits can be mistaken for seizures and because EEG abnormalities can persist even when seizures are controlled. Some children with uncontrollable seizures have been placed on a ketogenic diet, and this may be helpful in some cases. Occasionally, vagal nerve stimulation has been used.

Most children with AS do not receive drug therapy for hypermotoric or hyperactive behaviors, although some may benefit from the use of stimulant medications such as methylphenidate (Ritalin $\left.{ }^{\circledR}\right)$. Behavioral modification is effective in treating undesirable behaviors that are socially disruptive or self-injurious.

A full range of educational training and enrichment programs should be available. Unstable or nonambulatory children may benefit from physical therapy. Occupational therapy may help improve fine motor and oral-motor control. Special adaptive chairs or positioners may be required, especially for extremely ataxic children.

Speech therapy is essential and should focus on nonverbal methods of communication. Augmentative communication aids such as picture cards or communication boards should be used at the earliest appropriate time. Attempts to teach signing should begin as soon as the child is sufficiently attentive. Special physical provisions in the classroom, along with teacher aides or assistants, may be needed for effective class integration. Children with AS with excessive hypermotoric behaviors need an accommodating classroom space. Individualization and flexibility in the school are important educational strategies.

Many families construct safe but confining bedrooms to accommodate disruptive nighttime wakefulness. Use of diphenylhydramine or clonidine may be helpful. Administration of $0.3 \mathrm{mg}$ melatonin 1 hour before sleep may be helpful in some but should not be given in the middle of the night if the child awakens. ${ }^{130}$ Use of sedating agents such as phenothiazines and atypical antipsychotics is generally not advised because they cause negative side effects.

Orthopedic problems, particularly subluxed or pronated ankles or tight Achilles tendons, can be corrected by orthotic bracing or surgery. Thoraco-lumbar jackets may be needed for scoliosis, and individuals with severe curvature may benefit from surgical rod stabilization. Ambulation should be encouraged as individuals with severe scoliosis and ataxia may otherwise lose their ability to walk.

In later childhood obesity can occur. ${ }^{38}$ Food-related behaviors (e.g., eating nonfood items, apparent increased appetite, increased behavioral orientation to food) are common in $\mathrm{AS}^{131}$ and may contribute to obesity onset. Some weight gain can occur during young adulthood and obesity can be a management concern. Obesity appears to be more in those with UPD and IDs versus those with deletions. ${ }^{44}$ Severe (e.g., morbid) obesity is very uncommon occurrence in AS. Older adults tend to become less mobile and less active; attention to activity schedules may be helpful and may help reduce obesity.

\section{GENETIC COUNSELING}

The risk to the sibs of an individual with AS depends on the genetic mechanism of AS in the proband. The classification (Table 2) of mechanisms is based on terminology by Jiang et al. ${ }^{63}$

Ia: For mothers who have had an AS child with a de novo large deletion, the risk for AS in future offspring is $<1 \%$. This $1 \%$ figure embraces the fact that germline mosaicism for a large deletion has been reported on one occasion. ${ }^{132}$ Additionally, on rare occasions, the mother of an AS child has been shown to have a balanced chromosomal translocation that predisposes to AS recurrence. ${ }^{133,134}$ Thus, mothers of AS children with deletions can be offered blood chromosome and FISH testing to rule out a chromosome 15 rearrangement.

Ib: If a chromosome rearrangement or small gene region deletion has been identified in a proband, the risks to sibs and other family members depends on whether the rearrangement is inherited or de novo. ${ }^{133,135}$

IIa: In families in which AS is the result of paternal UPD and in which no Robertsonian chromosomal translocation is identified in the proband, the risk to sibs of having AS is $<1 \%$. This risk figure is based on the lack of recurrence among all known cases of UPD in AS with normal chromosomes, the experience with UPD in other disorders, and theoretical consideration regarding the mechanism of UPD. The recurrence risk is not zero, however, as recurrent meiotic nondisjunction of maternal chromosome 15 has been observed. ${ }^{136}$ In addition, if an individual has AS resulting from paternal UPD and has a normal karyotype, a chromosomal analysis of the mother should be offered to exclude the rare possibility that a Robertsonian translocation or marker chromosome was a predisposing factor (e.g., via generation of maternal gamete that was nullisomic for chromosome 15, with subsequent postzygotic "correction" to paternal disomy). 


\begin{tabular}{|c|c|c|c|}
\hline Molecular class & Families & Genetic mechanism & Risk to sibs \\
\hline Ia & $65-75 \%$ & 5-7 $\mathrm{Mb}$ deletion & $<1 \%$ \\
\hline $\mathrm{Ib}$ & $<1 \%$ & $\begin{array}{l}\text { Unbalanced chromosome translocation or } \\
\text { inherited small interstitial deletion }\end{array}$ & Possibly as high as $50 \%$ \\
\hline IIa & $3-7 \%$ & Paternal UPD & $<1 \%$ \\
\hline IIb & $<1 \%$ & $\begin{array}{l}\text { Paternal UPD with predisposing parental } \\
\text { translocation }\end{array}$ & $\begin{array}{l}\text { Approaching } 100 \% \text { if father has a } 15 ; 15 \\
\text { Robertsonian translocation }\end{array}$ \\
\hline IIIa & $0.5 \%$ & ID with deletion in the IC & As high as $50 \%$ if mother also has IC deletion \\
\hline IIIb & $2.5 \%$ & ID without deletion in the IC & $<1 \%$ \\
\hline IV & $11 \%$ & UBE3A mutation & As high as $50 \%$ if mother also has a mutation \\
\hline $\mathrm{V}$ & $10-15 \%$ & "Other"—no identifiable molecular abnormality & Undetermined risk \\
\hline
\end{tabular}

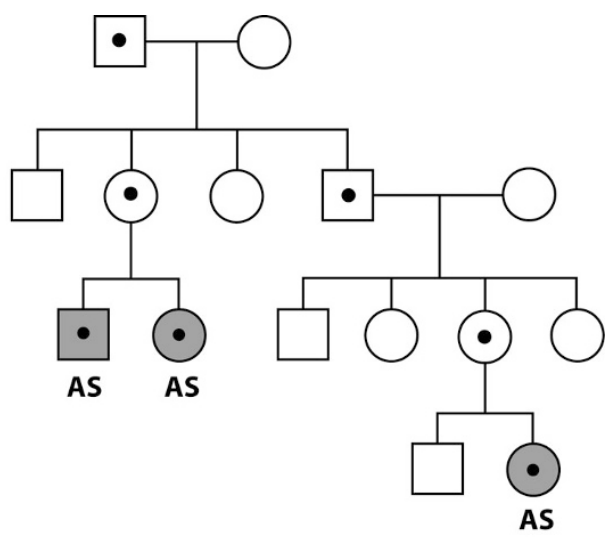

- = UBE3A mutation or IC deletion carrier

- = Angelman syndrome

Fig. 3. The pedigree illustrates how imprinting inheritance causes recurrence of $\mathrm{AS}$, sometimes in distant relatives. Inheritance of a UBE3A mutation or IC deletion from a male (top left) has no detectable effect on his offspring since they have inherited an active UBE3A gene from their mother. However, should carrier female offspring transmit the UBE3A mutation or IC deletion to any of their offspring, he/she will have AS since that child would also get an inactivated $U B E 3 A$ from their father.

IIb: Individuals with UPD should have chromosomal analysis to ensure that they do not have a paternally inherited Robertsonian translocation that would increase the family's recurrence risk.

IIIa: Individuals with an IC deletion can have a phenotypically normal mother who also has an IC deletion. In these situations, the mother has either acquired her IC deletion by a spontaneous mutation of her paternally derived chromosome 15 or inherited the IC deletion from her father, consistent with the imprinting mechanisms governing the $15 \mathrm{q} 11.2$-q13 region. ${ }^{105}$ Additionally, some of these mothers may have germline mosaicism for the IC deletion; this complicates genetic counseling when the mother of a proband with an IC deletion has normal peripheral blood IC genetic studies. If a proband's mother has a known IC deletion, the risk to the sibs is $50 \%$.
IIIb: All IDs without an IC deletion (except for one case of an IC rearrangement, refer to Buiting et al. ${ }^{105}$ ) have been in individuals with no known family history of AS and thus probably represent a de novo defect in the imprinting process in 15q11.2-q13 during the mother's oogenesis. ${ }^{137}$ Therefore, the risk to the sibs of a proband in such families is $<1 \%$.

IV: $U B E 3 A$ mutations can be inherited or de novo. $44,66,95,138$ In addition, several cases of germline mosaicism for a $U B E 3 A$ mutation have been noted. ${ }^{109}$ If a proband's mother has a $U B E 3 A$ mutation, the risk to the sibs is $50 \%$.

$\mathrm{V}$ : In this molecular class, clinical features of AS are present but an AS-causing genetic mechanism has not yet been identified.

If a $U B E 3 A$ mutation, IC deletion, or structural chromosomal rearrangement has been identified in the mother of the proband (or in the father in the case of UPD and Robertsonian translocations), family members can be offered genetic counseling and the option of genetic testing. If a proband's mother carries an IC deletion or $U B E 3 A$ mutation, the mother's sisters, for example, are at risk of carrying the IC deletion or the $U B E 3 A$ mutation. If there is then an unaffected carrier sister, there is a $50 \%$ risk of having AS in her offspring. Also, unaffected maternal uncles of the proband who are carriers are not at risk of having affected children themselves but are at risk of having affected grandchildren (Fig. 3).

\section{Prenatal diagnosis}

Prenatal detection of all the known molecular genetic alterations in the $15 \mathrm{q} 11.2-\mathrm{q} 13$ region is possible through DNA and/or chromosomal/FISH analysis of fetal cells obtained by chronic villus sampling (CVS) or amniocentesis. ${ }^{115,139}$ DNA methylation analysis (for 5-7 Mb deletions, UPD, and IC defects) on cells obtained by CVS is theoretically possible, ${ }^{115,139}$ but the few clinical laboratories doing prenatal testing using DNA methylation analysis prefer using amniocytes as a result of the relative hypomethylation of cells derived from the placenta. FISH analysis, IC deletion analysis, and sequence analysis of $U B E 3 A$ should be technically possible for CVS. Preimplantation genetic diagnosis may be available for families in which the underlying mechanism has been identified in the proband to be $U B E 3 A$ mutations or IC deletions. (The relative hypomethylation of the early embryo makes preimplantation genetic diagnosis problematic for DNA methylation testing.)

Routine screening amniocentesis (e.g., for advanced maternal age) may encounter abnormalities that place the fetus at risk for 
having AS. If a 15q11.2-q13 deletion is suspected on cytogenetic studies from CVS or amniocentesis, FISH or array-CGH studies are indicated to confirm the deletion. If the deletion is confirmed, parent-of-origin studies ${ }^{115,139}$ can be performed to determine if the deletion is maternally derived (fetus has AS) or paternally derived (fetus has PWS). If trisomy 15 or mosaic trisomy 15 is detected on CVS, and if subsequent amniocentesis reveals 46 chromosomes, the possibility of trisomy rescue leading to AS (paternal UPD) or PWS (maternal UPD) must be considered. In this instance, parent-of-origin (DNA) studies on amniocytes can be performed.

\section{ACKNOWLEDGMENTS}

The authors thank the many families of individuals with Angelman syndrome who have contributed to our research and educational efforts. Parental permission was obtained for use of the photographs of individuals shown in Figure 1.

\section{REFERENCES}

1. Clayton-Smith J, Pembrey ME. Angelman syndrome. J Med Genet 1992; 29:412-415.

2. Steffenburg S, Gillberg CL, Steffenburg U, Kyllerman M. Autism in Angelman syndrome: a population-based study. Pediatr Neurol 1996;14: 131-136.

3. Petersen MB, Brondum-Nielsen K, Hansen LK, Wulff K. Clinical, cytogenetic, and molecular diagnosis of Angelman syndrome: estimated prevalence rate in a Danish county. Am J Med Genet 1995;60:261-262.

4. Angelman H. 'Puppet' children. A report of three cases. Dev Med Child Neurol 1965;7:681-688.

5. Clayton-Smith J, Laan L. Angelman syndrome: a review of the clinical and genetic aspects. $J$ Med Genet 2003;40:87-95.

6. Van Buggenhout G, Fryns JP. Angelman syndrome (AS, MIM 105830). Eur J Hum Genet 2009; 17:1367-1373.

7. Williams CA, Beaudet AL, Clayton-Smith J, et al. Angelman syndrome 2005: updated consensus for diagnostic criteria. Am J Med Genet A 2006; 140:413-418

8. Zori RT, Hendrickson J, Woolven S, Whidden EM, Gray B, Williams CA Angelman syndrome: clinical profile. J Child Neurol 1992;7:270-280.

9. Williams CA, Zori RT, Hendrickson J, et al. Angelman syndrome. Curr Probl Pediatr 1995;25:216-231.

10. Fryburg JS, Breg WR, Lindgren V. Diagnosis of Angelman syndrome in infants. Am J Med Genet 1991;38:58-64.

11. Boyd SG, Harden A, Patton MA. The EEG in early diagnosis of the Angelman (happy puppet) syndrome. Eur J Pediatr 1988;147:508-513.

12. Korff CM, Kelley KR, Nordli DR Jr. Notched delta, phenotype, and Angelman syndrome. $J$ Clin Neurophysiol 2005;22:238-243.

13. Rubin DI, Patterson MC, Westmoreland BF, Klass DW. Angelman's syndrome: clinical and electroencephalographic findings. Electroencephalogr Clin Neurophysiol 1997;102:299-302

14. Galvan-Manso M, Campistol J, Conill J, Sanmarti FX. Analysis of the characteristics of epilepsy in 37 patients with the molecular diagnosis of Angelman syndrome. Epileptic Disord 2005;7:19-25.

15. Harting I, Seitz A, Rating D, et al. Abnormal myelination in Angelman syndrome. Eur J Paediatr Neurol 2009;13:271-276.

16. Castro-Gago M, Gomez-Lado C, Eiris-Punal J, Rodriguez-Mugico VM. Abnormal myelination in Angelman syndrome. Eur $J$ Paediatr Neurol 2010;14:292.

17. Meyer Witte S, Espil-Taris C, Cenraud C, et al. Angelman syndrome and intracranial aneurysm: fortuitous association or commune genetic predisposition? Arch Pediatr 2005;12:431-433.

18. Mastroyianni SD, Kontopoulos E. Split-cord malformation in a girl with Angelman syndrome: a mere coincidence? Am J Med Genet 2002;111:57-60.

19. Incorpora G, Cocuzza M, Mattina T. Angelman syndrome and vermian cyst. Am J Med Genet 1994;52:246-247.

20. Van Lierde A, Atza MG, Giardino D, Viani F. Angelman's syndrome in the first year of life. Dev Med Child Neurol 1990;32:1011-1016.

21. Stecker MM, Myers SM. Reserpine responsive myoclonus and hyperpyrexia in a patient with Angelman syndrome. Clin Neurol Neurosurg 2003; 105:183-187.

22. Harbord M. Levodopa responsive Parkinsonism in adults with Angelman Syndrome. J Clin Neurosci 2001;8:421-422.

23. Douchin S, Do-Ngoc D, Rossignol AM, Lucet V, Joannard A, Jouk PS Angelman syndrome and severe vagal hypertonia. Three pediatric case reports. Arch Mal Coeur Vaiss 2000;93:559-563.

24. Oiglane-Shlik E, Rein R, Tillmann V, Talvik T, Ounap K. A female with
Angelman syndrome and unusual limb deformities. Pediatr Neurol 2005; 33:66-69.

25. Katzos G, Triantafyllou P, Gombakis N, Sofocleous C, Zafeiriou DI Thelarche variant in a girl with Angelman syndrome. Brain Dev 2004;26: 339-341.

26. Deda G, Caksen H, Kansu A, et al. Toxic hepatitis in a case of Angelman syndrome associated with Lennox-Gastaut syndrome. Genet Couns 2004; 15:357-361.

27. Buntinx IM, Hennekam RC, Brouwer OF, et al. Clinical profile of Angelman syndrome at different ages. Am J Med Genet 1995;56:176-183.

28. Bruni O, Ferri R, D’Agostino G, Miano S, Roccella M, Elia M. Sleep disturbances in Angelman syndrome: a questionnaire study. Brain Dev 2004;26:233-240

29. Didden R, Korzilius H, Duker P, Curfs L. Communicative functioning in individuals with Angelman syndrome: a comparative study. Disabil Rehabil 2004:26:1263-1267.

30. Miano S, Bruni O, Leuzzi V, Elia M, Verrillo E, Ferri R. Sleep polygraphy in Angelman syndrome. Clin Neurophysiol 2004;115:938-945.

31. Walz NC, Beebe D, Byars K. Sleep in individuals with Angelman syndrome: parent perceptions of patterns and problems. Am J Ment Retard 2005; 110:243-252.

32. Walz NC. Parent report of stereotyped behaviors, social interaction, and developmental disturbances in individuals with Angelman syndrome. J Autism Dev Disord 2007;37:940-947.

33. Lee ST, Nicholls RD, Bundey S, Laxova R, Musarella M, Spritz RA. Mutations of the $\mathrm{P}$ gene in oculocutaneous albinism, ocular albinism, and Prader-Willi syndrome plus albinism. N Engl J Med 1994;330:529-534.

34. King RA, Wiesner GL, Townsend D, White JG. Hypopigmentation in Angelman syndrome. Am J Med Genet 1993;46:40-44.

35. Fridman C, Hosomi N, Varela MC, Souza AH, Fukai K, Koiffmann CP. Angelman syndrome associated with oculocutaneous albinism due to an intragenic deletion of the $\mathrm{P}$ gene. Am J Med Genet A 2003;119:180-183.

36. Trillingsgaard A, Ostergaard JR. Autism in Angelman syndrome: an exploration of comorbidity. Autism 2004;8:163-174.

37. Summers JA, Allison DB, Lynch PS, Sandler L. Behaviour problems in Angelman syndrome. J Intellect Disabil Res 1995;39(Pt 2):97-106.

38. Clayton-Smith J. Clinical research on Angelman syndrome in the United Kingdom: observations on 82 affected individuals. Am J Med Genet 1993; 46:12-15

39. Peters SU, Goddard-Finegold J, Beaudet AL, Madduri N, Turcich M, Bacino CA. Cognitive and adaptive behavior profiles of children with Angelman syndrome. Am J Med Genet A 2004;128:110-113.

40. Lossie AM, Driscoll DJ. Transmission of Angelman syndrome by an affected mother. Genet Med 1999;1:262-266.

41. Bjerre I, Fagher B, Ryding E, Rosen I. The Angelman or "happy puppet" syndrome. Clinical and electroencephalographic features and cerebral blood flow. Acta Paediatr Scand 1984:73:398-402.

42. Philippart M. Angelman syndrome from infancy to old age. In: Ninth Biennial Angelman Syndrome Conference. Anaheim, CA, 2005.

43. Fridman C, Varela MC, Kok F, Diament A, Koiffmann CP. Paternal UPD15: further genetic and clinical studies in four Angelman syndrome patients. Am J Med Genet 2000;92:322-327.

44. Lossie AC, Whitney MM, Amidon D, et al. Distinct phenotypes distinguish the molecular classes of Angelman syndrome. J Med Genet 2001;38:834845 .

45. Smith A, Marks R, Haan E, Dixon J, Trent RJ. Clinical features in four patients with Angelman syndrome resulting from paternal uniparental disomy. J Med Genet 1997;34:426-429.

46. Varela MC, Kok F, Otto PA, Koiffmann CP. Phenotypic variability in Angelman syndrome: comparison among different deletion classes and between deletion and UPD subjects. Eur J Hum Genet 2004;12:987-992.

47. Sahoo T, Bacino CA, German JR, et al Identification of novel deletions of 15q11q13 in Angelman syndrome by array-CGH: molecular characterization and genotype-phenotype correlations. Eur J Hum Genet 2007;15:943949

48. Saitoh S, Wada T, Okajima M, Takano K, Sudo A, Niikawa N. Uniparental disomy and imprinting defects in Japanese patients with Angelman syndrome. Brain Dev 2005;27:389-391.

49. Nazlican H, Zeschnigk M, Claussen U, et al. Somatic mosaicism in patients with Angelman syndrome and an imprinting defect. Hum Mol Genet 2004; $13: 2547-2555$

50. Zweier C, Thiel CT, Dufke A, et al. Clinical and mutational spectrum of Mowat-Wilson syndrome. Eur J Med Genet 2005;48:97-111.

51. Gilfillan GD, Selmer KK, Roxrud I, et al. SLC9A6 mutations cause $\mathrm{X}$-linked mental retardation, microcephaly, epilepsy, and ataxia, a phenotype mimicking Angelman syndrome. Am J Hum Genet 2008;82:10031010.

52. Christianson AL, Stevenson RE, van der Meyden CH, et al. X linked severe mental retardation, craniofacial dysmorphology, epilepsy, ophthalmoplegia, and cerebellar atrophy in a large South African kindred is localised to Xq24-q27. J Med Genet 1999;36:759-766. 
53. Spiegel EK, Colman RF, Patterson D. Adenylosuccinate lyase deficiency. Mol Genet Metab 2006;89:19-31.

54. Gitiaux C, Ceballos-Picot I, Marie S, et al. Misleading behavioural phenotype with adenylosuccinate lyase deficiency. Eur J Hum Genet 2009;17: 133-136.

55. Zweier C, Peippo MM, Hoyer J, et al. Haploinsufficiency of TCF4 causes syndromal mental retardation with intermittent hyperventilation (Pitt-Hopkins syndrome). Am J Hum Genet 2007;80:994-1001.

56. Peippo MM, Simola KO, Valanne LK, et al. Pitt-Hopkins syndrome in two patients and further definition of the phenotype. Clin Dysmorphol 2006; 15:47-54.

57. Watson P, Black G, Ramsden S, et al. Angelman syndrome phenotype associated with mutations in MECP2, a gene encoding a methyl CpG binding protein. J Med Genet 2001;38:224-248.

58. Precht KS, Lese CM, Spiro RP, et al. Two 22q telomere deletions serendipitously detected by FISH. J Med Genet 1998;35:939-942.

59. Williams SR, Mullegama SV, Rosenfeld JA, et al. Haploinsufficiency of MBD5 associated with a syndrome involving microcephaly, intellectual disabilities, severe speech impairment, and seizures. Eur J Hum Genet 2010;18:436-441.

60. van Bon BW, Koolen DA, Brueton L, et al. The 2q23.1 microdeletion syndrome: clinical and behavioural phenotype. Eur J Hum Genet 2010;18: $163-170$.

61. Sharkey FH, Morrison N, Murray R, et al. 17q21.31 microdeletion syndrome: further expanding the clinical phenotype. Cytogenet Genome Res 2009; 127:61-66

62. Brunetti-Pierri N, Berg JS, Scaglia F, et al. Recurrent reciprocal 1q21.1 deletions and duplications associated with microcephaly or macrocephaly and developmental and behavioral abnormalities. Nat Genet 2008; 40:1466-1471

63. Jiang Y, Lev-Lehman E, Bressler J, Tsai TF, Beaudet AL. Genetics of Angelman syndrome. Am J Hum Genet 1999;65:1-6.

64. Nicholls RD, Knepper JL. Genome organization, function, and imprinting in Prader-Willi and Angelman syndromes. Annu Rev Genomics Hum Genet 2001;2:153-175.

65. Kishino T, Lalande M, Wagstaff J. UBE3A/E6-AP mutations cause Angelman syndrome. Nat Genet 1997;15:70-73.

66. Matsuura T, Sutcliffe JS, Fang P, et al. De novo truncating mutations in E6-AP ubiquitin-protein ligase gene (UBE3A) in Angelman syndrome. Nat Genet 1997; 15:74-77.

67. Huibregtse JM, Scheffner M, Howley PM. Cloning and expression of the cDNA for E6-AP, a protein that mediates the interaction of the human papillomavirus E6 oncoprotein with p53. Mol Cell Biol 1993;13:775-784.

68. Scheffner M, Nuber U, Huibregtse JM. Protein ubiquitination involving an E1-E2-E3 enzyme ubiquitin thioester cascade. Nature 1995;373:81-83.

69. Ciechanover A, Schwartz AL. The ubiquitin-proteasome pathway: the complexity and myriad functions of proteins death. Proc Natl Acad Sci U $S$ A 1998;95:2727-2730.

70. Hershko A, Ciechanover A. The ubiquitin system. Annu Rev Biochem 1998;67:425-479.

71. Verdecia MA, Joazeiro CA, Wells NJ, et al. Conformational flexibility underlies ubiquitin ligation mediated by the WWP1 HECT domain E3 ligase. Mol Cell 2003;11:249-259.

72. Ramamoorthy S, Nawaz Z. E6-associated protein (E6-AP) is a dual function coactivator of steroid hormone receptors. Nucl Recept Signal 2008;6: e006.

73. Khan OY, Fu G, Ismail A, et al. Multifunction steroid receptor coactivator, E6-associated protein, is involved in development of the prostate gland. Mol Endocrinol 2006;20:544-559.

74. Kuhne C, Banks L. E3-ubiquitin ligase/E6-AP links multicopy maintenance protein 7 to the ubiquitination pathway by a novel motif, the $\mathrm{L} 2 \mathrm{G}$ box. J Biol Chem 1998;273:34302-34309.

75. Kumar S, Talis AL, Howley PM. Identification of HHR23A as a substrate for E6-associated protein-mediated ubiquitination. J Biol Chem 1999;274: $18785-18792$.

76. Li L, Li Z, Howley PM, Sacks DB. E6AP and calmodulin reciprocally regulate estrogen receptor stability. J Biol Chem 2006;281:1978-1985.

77. Oda H, Kumar S, Howley PM. Regulation of the Src family tyrosine kinase Blk through E6AP-mediated ubiquitination. Proc Natl Acad Sci U S A 1999;96:9557-9562.

78. Reiter LT, Seagroves TN, Bowers M, Bier E. Expression of the Rho-GEF $\mathrm{Pbl} / \mathrm{ECT} 2$ is regulated by the UBE3A E3 ubiquitin ligase. Hum Mol Genet 2006;15:2825-2835.

79. Shimoji T, Murakami K, Sugiyama Y, et al. Identification of annexin A1 as a novel substrate for E6AP-mediated ubiquitylation. J Cell Biochem 2009; 106:1123-1135.

80. Louria-Hayon I, Alsheich-Bartok O, Levav-Cohen Y, et al. E6AP promotes the degradation of the PML tumor suppressor. Cell Death Differ 2009;16: 1156-1166.

81. Dindot SV, Antalffy BA, Bhattacharjee MB, Beaudet AL. The Angelman syndrome ubiquitin ligase localizes to the synapse and nucleus, and ma- ternal deficiency results in abnormal dendritic spine morphology. Hum Mol Genet 2008; 17:111-118.

82. Lu Y, Wang F, Li Y, Ferris J, Lee JA, Gao FB. The Drosophila homologue of the Angelman syndrome ubiquitin ligase regulates the formation of terminal dendritic branches. Hum Mol Genet 2009;18:454-462.

83. Yashiro K, Riday TT, Condon $\mathrm{KH}$, et al. UBE3A is required for experience-dependent maturation of the neocortex. Nat Neurosci 2009;12:777783

84. Jiang $\mathrm{YH}$, Armstrong D, Albrecht U, et al. Mutation of the Angelman ubiquitin ligase in mice causes increased cytoplasmic p53 and deficits of contextual learning and long-term potentiation. Neuron 1998;21:799-811.

85. van Woerden GM, Harris KD, Hojjati MR, et al. Rescue of neurological deficits in a mouse model for Angelman syndrome by reduction of alphaCaMKII inhibitory phosphorylation. Nat Neurosci 2007;10:280-282.

86. Weeber EJ, Jiang YH, Elgersma Y, et al. Derangements of hippocampal calcium/calmodulin-dependent protein kinase II in a mouse model for Angelman mental retardation syndrome. J Neurosci 2003;23:2634-2644.

87. Herzing LB, Kim SJ, Cook EH Jr, Ledbetter DH. The human aminophospholipid-transporting ATPase gene ATP10C maps adjacent to $U B E 3 A$ and exhibits similar imprinted expression. Am J Hum Genet 2001;68:15011505 .

88. Rougeulle C, Glatt H, Lalande M. The Angelman syndrome candidate gene, UBE3A/E6-AP, is imprinted in brain. [letter]. Nat Genet 1997;17: $14-15$.

89. $\mathrm{Vu} \mathrm{TH}$, Hoffman AR. Imprinting of the Angelman syndrome gene, $U B E 3 A$, is restricted to brain. [letter.] Nat Genet 1997;17:12-13.

90. Albrecht U, Sutcliffe JS, Cattanach BM, et al. Imprinted expression of the murine Angelman syndrome gene, $U B E 3 A$, in hippocampal and Purkinje neurons. Nat Genet 1997; 17:75-78.

91. Yamasaki K, Joh K, Ohta T, et al. Neurons but not glial cells show reciprocal imprinting of sense and antisense transcripts of UBE3A. Hum Mol Genet 2003;12:837-847.

92. Herzing LB, Cook EH Jr, Ledbetter DH. Allele-specific expression analysis by RNA-FISH demonstrates preferential maternal expression of $U B E 3 A$ and imprint maintenance within 15q11-q13 duplications. Hum Mol Genet 2002;11:1707-1718.

93. Rougeulle C, Cardoso C, Fontes M, Colleaux L, Lalande M. An imprinted antisense RNA overlaps $U B E 3 A$ and a second maternally expressed transcript. [letter]. Nat Genet 1998;19:15-16.

94. Runte M, Huttenhofer A, Gross S, Kiefmann M, Horsthemke B, Buiting K. The IC-SNURF-SNRPN transcript serves as a host for multiple small nucleolar RNA species and as an antisense RNA for UBE3A. Hum Mol Genet 2001;10:2687-2700.

95. Kishino T, Wagstaff J. Genomic organization of the UBE3A/E6-AP gene and related pseudogenes. Genomics 1998;47:101-107.

96. Yamamoto Y, Huibregtse JM, Howley PM. The human E6-AP gene $(U B E 3 A)$ encodes three potential protein isoforms generated by differential splicing. Genomics 1997;41:263-266.

97. Amos-Landgraf JM, Ji Y, Gottlieb W, et al. Chromosome breakage in the Prader-Willi and Angelman syndromes involves recombination between large, transcribed repeats at proximal and distal breakpoints. Am J Hum Genet 1999;65:370-386.

98. Christian SL, Fantes JA, Mewborn SK, Huang B, Ledbetter DH. Large genomic duplicons map to sites of instability in the Prader-Willi/Angelman syndrome chromosome region (15q11-q13). Hum Mol Genet 1999;8: $1025-1037$.

99. Knoll JH, Nicholls RD, Magenis RE, et al. Angelman syndrome: three molecular classes identified with chromosome 15q11q13-specific DNA markers. Am J Hum Genet 1990;47:149-155.

100. Pujana MA, Nadal M, Guitart M, Armengol L, Gratacos M, Estivill X. Human chromosome $15 \mathrm{q} 11-\mathrm{q} 14$ regions of rearrangements contain clusters of LCR15 duplicons. Eur J Hum Genet 2002;10:26-35.

101. Gimelli G, Pujana MA, Patricelli MG, et al. Genomic inversions of human chromosome $15 \mathrm{q} 11-\mathrm{q} 13$ in mothers of Angelman syndrome patients with class II (BP2/3) deletions. Hum Mol Genet 2003;12:849-858.

102. Boyar FZ, Whitney MM, Lossie AC, et al. A family with a grandmaternally derived interstitial duplication of proximal 15q. Clin Genet 2001;60:421-430.

103. Bottani A, Robinson WP, DeLozier-Blanchet CD, et al. Angelman syndrome due to paternal uniparental disomy of chromosome 15: a milder phenotype? Am J Med Genet 1994;51:35-40.

104. Robinson WP, Christian SL, Kuchinka BD, et al. Somatic segregation errors predominantly contribute to the gain or loss of a paternal chromosome leading to uniparental disomy for chromosome 15. Clin Genet 2000; 57:349-358.

105. Buiting K, Barnicoat A, Lich C, Pembrey M, Malcolm S, Horsthemke B. Disruption of the bipartite imprinting center in a family with Angelman syndrome. Am J Hum Genet 2001;68:1290-1294.

106. Buiting K, Gross S, Lich C, Gillessen-Kaesbach G, el-Maarri O, Horsthemke B. Epimutations in Prader-Willi and Angelman syndromes: a molecular study of 136 patients with an imprinting defect. Am J Hum Genet 
$2003 ; 72 \cdot 571-577$

107. Glenn CC, Nicholls RD, Robinson WP, et al. Modification of $15 \mathrm{q} 11-\mathrm{q} 13$ DNA methylation imprints in unique Angelman and Prader-Willi patients. Hum Mol Genet 1993;2:1377-1382.

108. Buiting K, Lich C, Cottrell S, Barnicoat A, Horsthemke B. A 5-kb imprinting center deletion in a family with Angelman syndrome reduces the shortest region of deletion overlap to 880 bp. Hum Genet 1999;105:665666.

109. Malzac P, Webber H, Moncla A, et al. Mutation analysis of UBE3A in Angelman syndrome patients. Am J Hum Genet 1998;62:1353-1360.

110. The Human Gene Mutation Database (HGMD). Cardiff, UK: The Institute of Medical Genetics, 2010. Available at: http://www.hgmd.cf.ac.uk. Accessed January 15, 2010.

111. Boyes L, Wallace AJ, Krajewska-Walasek M, Chrzanowska KH, ClaytonSmith J, Ramsden S. Detection of a deletion of exons 8-16 of the UBE3A gene in familial Angelman syndrome using a semi-quantitative dosage PCR based assay. Eur J Med Genet 2006;49:472-480.

112. Lawson-Yuen A, Wu BL, Lip V, Sahoo T, Kimonis V. Atypical cases of Angelman syndrome. Am J Med Genet A 2006;140:2361-2364.

113. Sato K, Iwakoshi M, Shimokawa O, et al. Angelman syndrome caused by an identical familial 1,487-kb deletion. Am J Med Genet A 2007;143:98101.

114. Glenn CC, Saitoh S, Jong MT, et al. Gene structure, DNA methylation, and imprinted expression of the human SNRPN gene. Am J Hum Genet 1996; 58:335-346.

115. Kubota T, Das S, Christian SL, Baylin SB, Herman JG, Ledbetter DH. Methylation-specific PCR simplifies imprinting analysis. Nat Genet 1997; 16:16-17.

116. Zeschnigk M, Lich C, Buiting K, Doerfler W, Horsthemke B. A single-tube PCR test for the diagnosis of Angelman and Prader-Willi syndrome based on allelic methylation differences at the SNRPN locus. Eur J Hum Genet 1997;5:94-98.

117. White HE, Durston VJ, Harvey JF, Cross NC. Quantitative analysis of SNRPN (correction of SRNPN) gene methylation by pyrosequencing as a diagnostic test for Prader-Willi syndrome and Angelman syndrome. Clin Chem 2006;52:1005-1013.

118. Nygren AO, Ameziane N, Duarte HM, et al. Methylation-specific MLPA (MS-MLPA): simultaneous detection of CpG methylation and copy number changes of up to 40 sequences. Nucleic Acids Res 2005;33:e128.

119. Procter M, Chou LS, Tang W, Jama M, Mao R. Molecular diagnosis of Prader-Willi and Angelman syndromes by methylation-specific melting analysis and methylation-specific multiplex ligation-dependent probe amplification. Clin Chem 2006;52:1276-1283.

120. Dikow N, Nygren AO, Schouten JP, et al. Quantification of the methylation status of the PWS/AS imprinted region: comparison of two approaches based on bisulfite sequencing and methylation-sensitive MLPA. Mol Cell Probes 2007;21:208-215.

121. Martinez F, Leon AM, Monfort S, Oltra S, Rosello M, Orellana C. Robust, easy, and dose-sensitive methylation test for the diagnosis of Prader-Willi and Angelman syndromes. Genet Test 2006;10:174-177.
122. Fang $\mathrm{P}$, Lev-Lehman $\mathrm{E}$, Tsai TF, et al. The spectrum of mutations in UBE3A causing Angelman syndrome. Hum Mol Genet 1999;8:129-135.

123. Thibert RL, Conant KD, Braun EK, et al. Epilepsy in Angelman syndrome: a questionnaire-based assessment of the natural history and current treatment options. Epilepsia 2009;50:2369-2376.

124. Kuenzle C, Steinlin M, Wohlrab G, Boltshauser E, Schmitt B. Adverse effects of vigabatrin in Angelman syndrome. Epilepsia 1998;39:12131215

125. Laan LA, Renier WO, Arts WF, et al. Evolution of epilepsy and EEG findings in Angelman syndrome. Epilepsia 1997;38:195-199.

126. Nolt DH, Mott JM, Lopez WL. Assessment of anticonvulsant effectiveness and safety in patients with Angelman's syndrome using an Internet questionnaire. Am J Health Syst Pharm 2003;60:2583-2587.

127. Valente KD, Koiffmann CP, Fridman C, et al. Epilepsy in patients with angelman syndrome caused by deletion of the chromosome 15q11-13. Arch Neurol 2006;63:122-128.

128. Ostergaard JR, Balslev T. Efficacy of different antiepileptic drugs in children with Angelman syndrome associated with 15q11-13 deletion: the Danish experience. Dev Med Child Neurol 2001;43:718-719.

129. Pelc K, Boyd SG, Cheron G, Dan B. Epilepsy in Angelman syndrome. Seizure 2008;17:211-217.

130. Zhdanova IV, Wurtman RJ, Wagstaff J. Effects of a low dose of melatonin on sleep in children with Angelman syndrome. J Pediatr Endocrinol Metab 1999;12:57-67.

131. Barry RJ, Leitner RP, Clarke AR, Einfeld SL. Behavioral aspects of Angelman syndrome: a case control study. Am J Med Genet A 2005;132: $8-12$.

132. Kokkonen H, Leisti J. An unexpected recurrence of Angelman syndrome suggestive of maternal germ-line mosaicism of $\operatorname{del}(15)(\mathrm{q} 11 \mathrm{q} 13)$ in a Finnish family. Hum Genet 2000;107:83-85.

133. Horsthemke B, Maat-Kievit A, Sleegers E, et al. Familial translocations involving $15 \mathrm{q} 11-\mathrm{q} 13$ can give rise to interstitial deletions causing PraderWilli or Angelman syndrome. J Med Genet 1996;33:848-851.

134. Hulten M, Armstrong S, Challinor P, et al. Genomic imprinting in an Angelman and Prader-Willi translocation family. Lancet 1991;338:638639

135. Stalker HJ, Williams CA. Genetic counseling in Angelman syndrome: the challenges of multiple causes. Am J Med Genet 1998;77:54-59.

136. Harpey JP, Heron D, Prudent M, et al. Recurrent meiotic nondisjunction of maternal chromosome 15 in a sibship. Am J Med Genet 1998;76:103-104.

137. Buiting K, Dittrich B, Gross S, et al. Sporadic imprinting defects in Prader-Willi syndrome and Angelman syndrome: implications for imprintswitch models, genetic counseling, and prenatal diagnosis. Am J Hum Genet 1998;63:170-180.

138. Burger J, Horn D, Tonnies H, Neitzel H, Reis A. Familial interstitial 570 $\mathrm{kbp}$ deletion of the $U B E 3 A$ gene region causing Angelman syndrome but not Prader-Willi syndrome. Am J Med Genet 2002;111:233-237.

139. Glenn CC, Deng G, Michaelis RC, et al. DNA methylation analysis with respect to prenatal diagnosis of the Angelman and Prader-Willi syndromes and imprinting. Prenat Diagn 2000;20:300-306. 